\title{
Simulation of Induction Machine Drive by Composite Model Flux Observer
}

\author{
First A. Morteza Fazly and Second B. Seyed Zeinolabedin Moussavi
}

\begin{abstract}
This paper presents a robust simulation of direct vector control of induction machine (IM) drive on the rotor flux direction with composite model flux observer. In the indirect vector control of IM, current reference values are used for estimation angle of the rotor flux space vector (ARFSV), however using current reference values instead of current real values can decrease accuracy of ARFSV. In the direct vector control, current real values (current feedback) estimate the ARFSV. ARFSV estimation can be performed by current model flux observer and voltage model flux observer. These observers have their own limitations. The composite model reduces disadvantages of every individual ones. Simulation of composite model is applied to induction machines and obtained results compare to the classical current and voltage models. The composite model approach shows great advantages over those classic ones, a.e. speed control over wide range of motor operation and enough short settling time. All these remarkable advantages support application of composite model in ARFSV.
\end{abstract}

Index Terms - Direct Control, Induction Machine (IM) drive, Composite Model Flux Observer, Estimation angle of the rotor flux space vector.

\section{INTRODUCTION}

Induction machines are the most used converters in home appliances. The vector control theory is nowadays usually applied in controlled drives with induction machines where high dynamic and static speed or position control performances are required. Regardless of chosen control strategy (direct or indirect vector control, acting on stator terminal voltages or currents, maintaining the modulus of stator, rotor, or air gap flux vector constant) rotor position or speed sensor is commonly applied. Recently, there has been a lot of research effort spent in order to exclude rotor position for speed control purpose.

In our work the stator current needed to implement the feedback loops for induction motors speed control is applied as shows in Fig.1. The angle of the rotor flux space vector (ARFSV) is not measured but estimated. Accurate estimation of the rotor flux angle requires acceptable performance of Field Oriented Control (FOC), from that estimation also the frequency needed in the control law, $\omega_{1}$ should be derived. Meanwhile imperfect field-orientation introduces cross coupling as e.g. a voltage applied to affect only the current in the d-direction in reality affects both current components.

Manuscript received October 9, 2010.

F. A. Morteza Fazly is with the Electrical Engineering Department, Sharif University of Technology, Tehran, Iran. (e-mail: fazly@ee.sharif.ir).

S. B. Seyed.Z.Moussavi is with the Electrical Engineering Department, Shahid Rajaee Teacher Training University, Tehran, Iran (e-mail: smoussavi@srttu.edu).
Transformations between the coordinate systems of the rotor and stator are explicitly shown In Fig.1 as well as the fact that a three-phase Voltage Source Inverter (VSI) is used to generate the stator voltages. The observer block is hence used to indirectly estimate $\operatorname{ARFSV}\left(\chi_{\mathrm{r}}\right)$, via the already derived frequency $\omega_{1}$ is called Indirect Field-Orientation (IFO). It has been shown in [1] that the CM with IFO is quite robust to model errors with regards to stability.

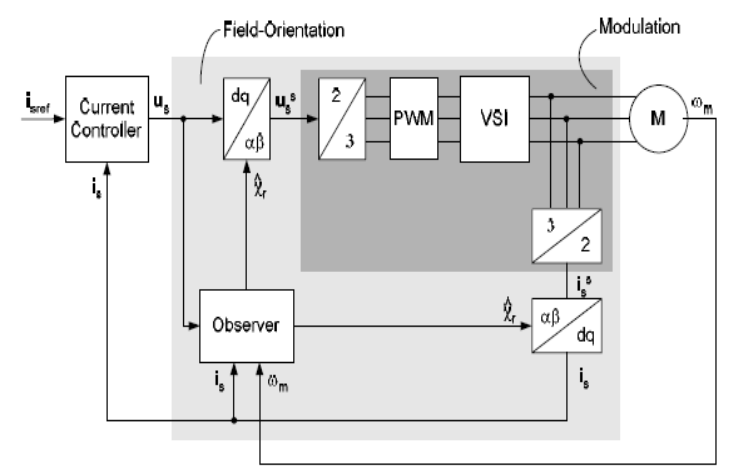

Fig.1 Illustration of current control where coordinate transformations are explicitly shown.

Imperfect parameter estimation by conventional current model leads to deteriorated system performance. The current model (CM) is sensitive to $R r$ and $L m$. Note that also the estimate of $L m$ affects the performance with the IFO implementation of CM. By using so-called Direct Field-Orientation (DFO), $\chi_{\mathrm{r}}$ is obtained by directly estimating the rotor flux. This estimator corresponds to a simulation of the rotor flux equation with the stator current as input. This model is therefore referred to as the CM. The current model may also be implemented by using the rotor flux equation in estimated rotor flux coordinates. By separating this equation into real and imaginary parts, we may hence estimate the derivative of the rotor flux angle as $\chi_{\text {r. where we }}$ approximated the rotor flux and the quadrature stator current component by their reference values (the estimated flux reference converges to its constant reference value and the current controllers make the current reference follow their reference values).

From the equivalent circuit diagram in induction machine model we may also express the rotor flux in terms of the stator voltage. We then obtain the so-called voltage model (VM), at high speeds; the voltage model gives an accurate stator flux estimate, since the back EMF dominates the stator voltage. However, at low and zero speed, the voltage model is well known to give non-satisfactory performance. This is due to sensitivity to the voltage drop across the stator resistance and to inherent signal integration problems at low excitation frequencies, see [2] and [3]. A further problem with stator 
flux estimation is that this equation cannot be directly used in practice as it contains a pure integration. This gives a marginally stable system due to the pole at the origin (this pole corresponds to a pole pair at $\pm \mathrm{j} \omega 1$ in a real-valued representation in synchronous or polar coordinates). Also, integration may give integrator drift, see e.g. [4]. To solve the integration problem, the pure integration can be replaced by a low-pass filter. In this case also the static effect of the filter should be compensated for as is done with the Statically Compensated Voltage Model (SCVM), see [5]. Due to the problems with VM at low speeds, the rotor flux is here preferably estimated using the current model, while the voltage model is suitable at higher speeds, see e.g. [6], [7] and [8]. By combining CM and VM what is called Composite Model flux observer we tried to illustrate advantages of each individual at low and high speed performance using simulation in Matlab/Simulink. We conclude that this combination demonstrates more accurate rotor flux angle estimation $\left(\chi_{\mathrm{r}}\right)$ over the entire motor speed range.

This simulation shows operation in base speed region. Simulation design is modeled in K-coordinate system with $\mathrm{AB}$ components, however rotor coordinate system with dq components as a special kind of K-coordinate is implemented.

\section{SySTEM MODELING}

\section{A. Dynamic Model of Induction Machine}

Mathematically, the induction motor can be compactly described by using complex-valued space vectors. From the definition of a space vector in synchronous coordinates and the expression for the derivatives, it follows that the two motor vector equations (1) and (2), are:

$$
\begin{aligned}
& \mathrm{L}_{\mathrm{v}} \frac{\mathrm{d}}{\mathrm{dt}} \mathrm{i}_{\mathrm{g}}(\mathrm{t})=\mathrm{u}_{\mathrm{g}}(\mathrm{t})-\left(\mathrm{R}_{\mathrm{g}}+\mathrm{R}_{\mathrm{r}}+j \mathrm{~L}_{\mathrm{g}} \omega_{1}(\mathrm{t})\right) \mathrm{i}_{\mathrm{g}}(\mathrm{t})-\left(j \mathrm{j}_{\mathrm{p}} \omega_{\mathrm{m}}-\frac{\mathrm{R}_{\mathrm{r}}}{\mathrm{L}_{\mathrm{m}}}\right) \psi_{\mathrm{r}}(\mathrm{t}) \\
& \frac{\mathrm{d}}{\mathrm{dt}} \Psi_{\mathrm{r}}(\mathrm{t})= \\
& \mathrm{R}_{\mathrm{r}} \mathbf{i}_{\mathrm{g}}(\mathrm{t})-\left(\frac{\mathrm{R}_{\mathrm{r}}}{\mathrm{L}_{\mathrm{m}}}+\mathrm{j}\left(\omega_{\mathrm{I}}(\mathrm{t})-\mathrm{n}_{\mathrm{p}} \omega_{\mathrm{m}}(\mathrm{t})\right)\right) \Psi_{\mathrm{r}}(\mathrm{t})
\end{aligned}
$$

The torque Eq. (3), may now be represented as

$$
\mathrm{T}(\mathrm{t})=\frac{3}{2} \mathrm{n}_{\mathrm{p}} \operatorname{Im}\left\{\psi_{\mathrm{r}}^{*}(\mathrm{t}) \mathrm{i}_{\mathrm{s}}(\mathrm{t})\right\}
$$

The synchronous coordinates are often chosen as rotor flux coordinates, i.e., $\theta_{1}$ is chosen as the angle of the rotor flux space vector. In rotor flux coordinates, the q-component of the flux therefore is zero by definition. By splitting equations (1), (2) and (3) in to real and imaginary part we get,

$$
\begin{aligned}
& \frac{\mathrm{d}}{\mathrm{dt}} \Psi_{s \mathrm{~s}}(\mathrm{t})=-\frac{\mathrm{R}_{\mathrm{s}}}{\mathrm{\sigma L}}\left(\Psi_{\mathrm{sd}}-\frac{\mathrm{L}_{\mathrm{m}}}{\mathrm{L}_{\mathrm{r}}} \Psi_{\mathrm{rd}}\right)+\omega_{\mathrm{s}} \Psi_{\mathrm{sq}}(\mathrm{t})+\mathrm{u}_{\mathrm{sd}}(\mathrm{t}) \\
& \frac{\mathrm{d}}{\mathrm{dt}} \Psi_{s q}(\mathrm{t})=-\frac{\mathrm{R}_{s}}{\sigma \mathrm{L}_{s}}\left(\Psi_{s \mathrm{~s}}-\frac{\mathrm{L}_{\mathrm{m}}}{\mathrm{L}_{\mathrm{T}}} \Psi_{\mathrm{rq}}\right)-\omega_{s} \Psi_{s \mathrm{~s}}(\mathrm{t})+\mathrm{u}_{\mathrm{sq}}(\mathrm{t}) \\
& \frac{\mathrm{d}}{\mathrm{dt}} \Psi_{\mathrm{rd}}(\mathrm{t})=-\frac{\mathrm{R}_{\mathrm{r}}}{\mathrm{\sigma L}_{\mathrm{T}}}\left(\Psi_{\mathrm{rd}}-\frac{\mathrm{L}_{\mathrm{m}}}{\mathrm{L}_{\mathrm{g}}} \Psi_{\mathrm{sd}}\right)+\omega_{\mathrm{r}} \Psi_{\mathrm{rq}}(\mathrm{t})+\mathrm{u}_{\mathrm{rd}}(\mathrm{t}) \\
& \frac{d}{d t} \psi_{r q}(t)=-\frac{R_{r}}{\sigma_{L}}\left(\psi_{\mathrm{rq}}-\frac{\mathrm{L}_{\mathrm{m}}}{\mathrm{L}_{\mathrm{g}}} \psi_{\mathrm{sq}}\right)+\omega_{\mathrm{r}} \psi_{\mathrm{rd}}(\mathrm{t})+\mathrm{u}_{\mathrm{rq}}(\mathrm{t})
\end{aligned}
$$

$$
\begin{aligned}
& \text { And } \\
& T(t)=\frac{3}{2} n_{p} \frac{L_{m}}{\sigma L_{s} L_{T}}\left\{\psi_{r d}(t) \Psi_{s q}(t)-\psi_{r q}(t) \psi_{s d}(t)\right\}
\end{aligned}
$$

Simulink induction machine models are available in the literature [9-11], but they appear to be block-boxes with no internal details. Some of them [9-11] recommend using S-functions, which are software source codes for Simulink blocks. This technique does not fully utilize the power and ease of Simulink because S-function programming knowledge is required to access the model variables. S-function run faster than discrete Simulink blocks, but Simulink models can be made to run faster using 'accelerator' functions or producing stand- alone Simulink models.

\section{B. Sensors Model}

Current, flux and speed sensors are modeled with a pole and a gain.

$$
\frac{k}{1+T s}
$$

\section{Power Electronics Converter Model}

The control input to the induction motor is the three-phase stator voltage which is generated through the voltage source inverter. A three phase voltage source inverter is depicted in Fig. 2 consisting of three legs, one for each phase. The legs contain IGBTs (Insulated Gate Bipolar Transistor) in parallel with diodes.

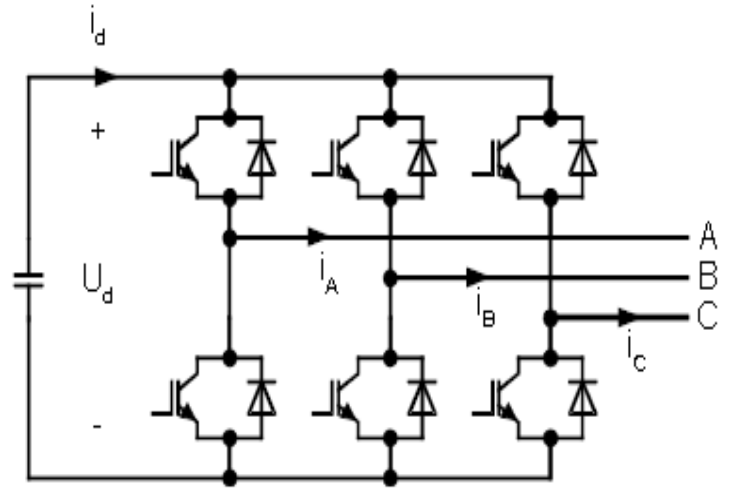

Fig. 2 Three-phase voltage source inverter.

With two possible positions of each of the six switches, the inverter in Fig. 2 may be put in eight different states. Two of these inverter states result in zero stator voltage. These are the combinations with all switches in the upper position or all switches in the lower position. The corresponding (zero) space vectors are sometimes referred to as the zero voltages. The remaining six non-zero stator voltage space vectors are shown in Fig. 3, where the length of each vector is $2 / 3 U_{d}$.

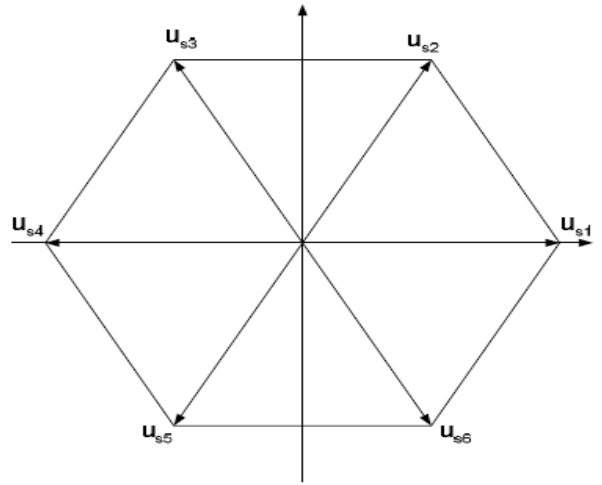

Fig. 3 The vectors us 1 - us6 represent the six non-zero stator voltage space vectors that can be generated by the three-phase voltage source inverter. 
The three (physical) stator voltages $\mathrm{u}_{\mathrm{A}}(\mathrm{t}), \mathrm{u}_{\mathrm{B}}(\mathrm{t})$ and $\mathrm{u}_{\mathrm{C}}(\mathrm{t})$ can be obtained from a space vector by projecting it into unit vectors in the directions of $\mathbf{u}_{\mathrm{s} 1}$, $\mathbf{u}_{\mathrm{s} 3}$ and $\mathbf{u}_{\mathrm{s} 5}$ in Fig.3. For example this means that the real part of a space vector corresponds to the A-component of the three-phase quantity.

\section{Control System Model}

\section{1) Current controller}

According to the equivalent circuit diagram in induction machine model the designed current control loop on axis-A is shown in Fig. 4. Designed of current control loop on axis $-\mathrm{B}$ is equivalent.

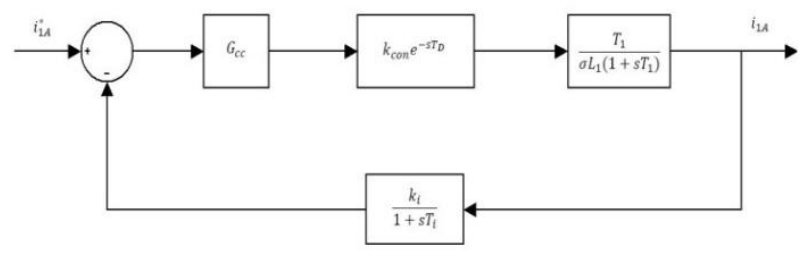

Fig.4 Current control loop on axis $-\mathrm{A}$

In Fig.4, converter is modeled with a delay $(\mathrm{Td}=0.1 \mathrm{~ms})$. Since of dead time between pulses are seldom, it is negligible.

Warning: we cannot compensate pole of converter.

With using of optimum margin method we have,

$$
\mathrm{G}_{\mathrm{cc}}(\mathrm{s})=\frac{\sigma \mathrm{L}_{1}\left(1+s \mathrm{~T}_{1}\right)}{s \mathrm{~T}_{1} \mathrm{~T}_{\mathrm{di \textrm {i }}} \mathrm{k}_{\mathrm{con}} \mathrm{k}_{\mathrm{i}}}
$$

By replacing $G_{c c}(s)$, transfer function $i_{1 A}$ to $i_{1 A}^{*}$ be is of order two. For sake of simplicity, the approximate transfer function is:

A. $\frac{i_{1 . A}}{i_{1, a}^{*}}=\frac{i_{1 B}}{i_{1 B}^{*}}=\frac{1 / k_{i \mathrm{i}}}{1+B T_{\text {oi }}}$

2) Flux controller

According to the equivalent circuit diagram in induction machine model, with swap current controller transfer function in flux control loop, flux control loop on axis $-\mathrm{A}$ are designed in Fig. 5 in the following figure.

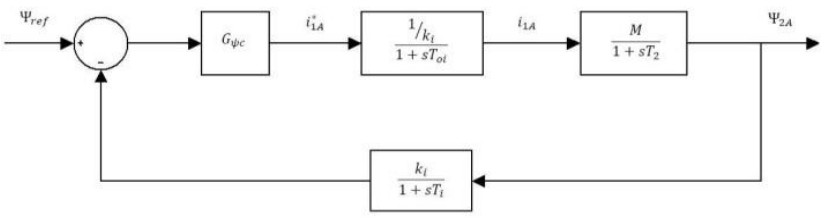

Fig. 5 Current control loop on axis $-\mathrm{A}$

By using optimum margin method, we have:

$$
\mathrm{G}_{\mathrm{quc}}(\mathrm{s})=\frac{\left(1+\mathrm{sT} \mathrm{T}_{\mathrm{pi}}\right)\left(1+\mathrm{sT} \mathrm{T}_{2)}\right.}{\mathrm{sT}_{\mathrm{oq}} \mathrm{MI}}
$$

3) Speed controller

Designed speed control loop is shown in Fig.6.

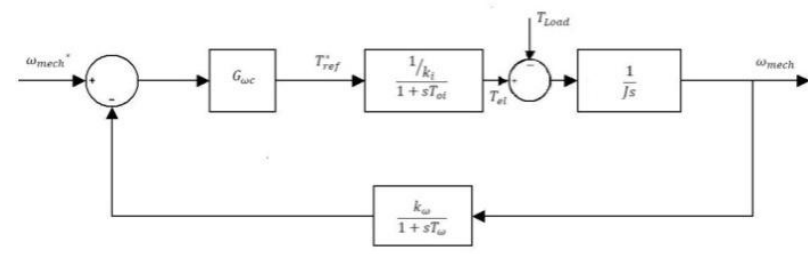

Fig. 6 Speed control loop

Assume maximum speed is equal to synchronous speed .In this method current on axis-A control the flux and current on axis-B control the torque, and in base speed region flux must be maximum and current on axis-A is constant . Therefore control loop on axis-B is active. Since band width of current control loop is greater than speed control loop, transfer function of current control loop with an approximate assumption is $\frac{1 d_{k_{\mathrm{i}}}}{1+s T_{\text {oi }}}$.

By using optimum polar method, we have:

$\mathrm{G}_{\omega c}(\mathrm{~s})=\frac{\mathrm{k}_{\mathrm{c}}\left(1+s \mathrm{~T}_{\mathrm{c}}\right)}{s \mathrm{~T}_{\mathrm{c}}}$

\section{SIMULINK IMPLEMENTATION}

\section{A. Simulation of Induction Machine Dynamic Model}

In this paper, simulink models are not used, the model of elements earned from equations. Complete model of induction machine is shown in Fig.7, induction machine model have three main parts: electrical model, mechanical model and transfers block .transfers block convert phase parameter to $\mathrm{AB}$ component of $\mathrm{K}$ - coordinate.

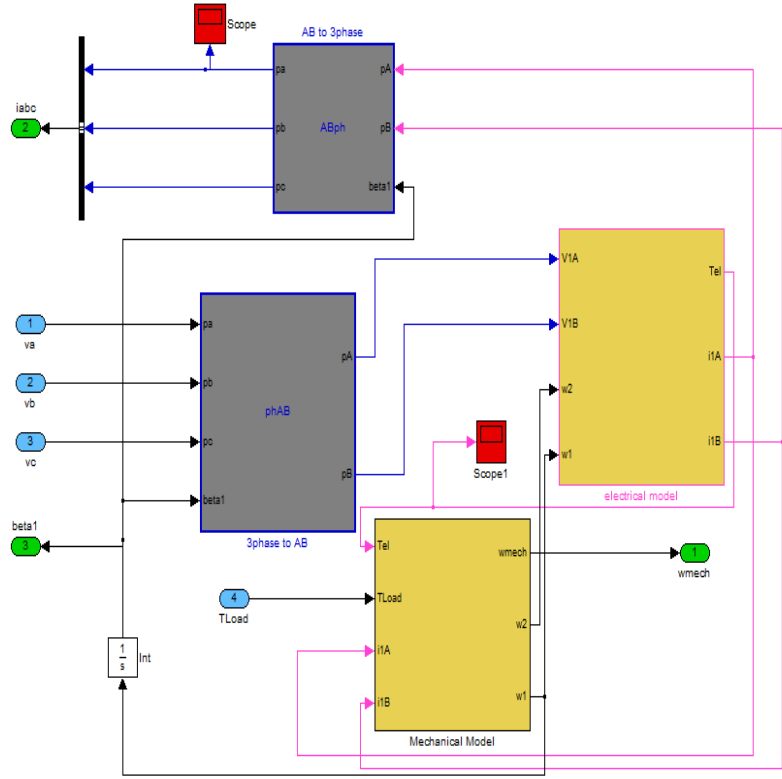

Fig. 7 Complete block diagram of induction machine dynamic model

Electrical part of induction machine model is shown in Fig. 8. This model obtains from implementation of Eqs. (4) and (5). 


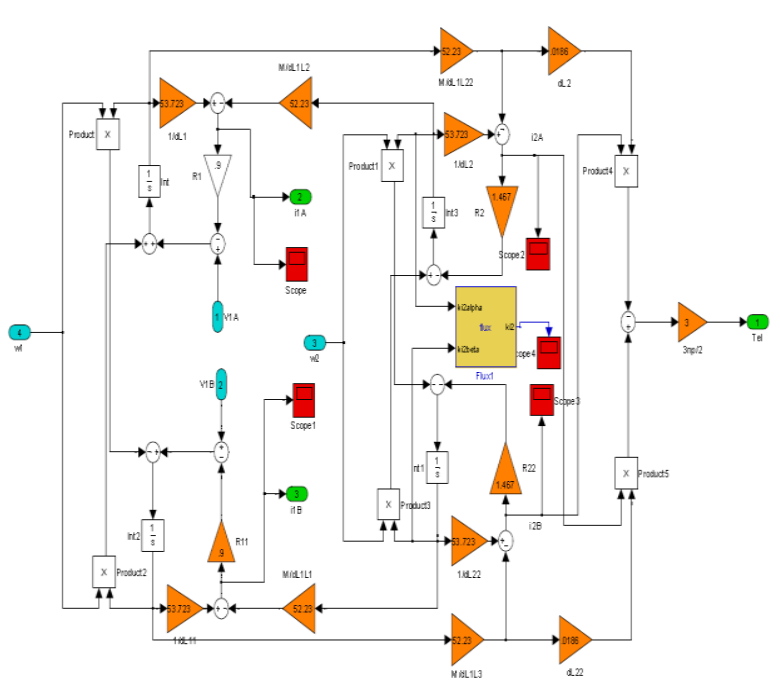

Fig. 8 Block diagram of electrical part of induction machine model

Input parameters are $V_{s d} \cdot V_{s q} \cdot \omega_{s}$ and $\omega_{\mathrm{r}}$ (rotor flux speed toward rotor reference). Parameters $V_{s d}$ and $V_{s q}$ be found from transfer block (phase to $\mathrm{AB}$ ) and $\omega_{g}, \omega_{r}$ comes from mechanical part of induction machine model. From block diagram of electric part of induction machine, electric torque $\left(T_{e \mathbb{l}}\right), i_{\varepsilon d}$ and $i_{\varepsilon q}$ are be found then $T_{e l}$ straight and $i_{\varepsilon d}$ and $i_{\varepsilon q}$ with transmission of transfer block (phase to AB) go to the mechanical part of induction machine. Block diagram of mechanical part is shown in Fig. 9.

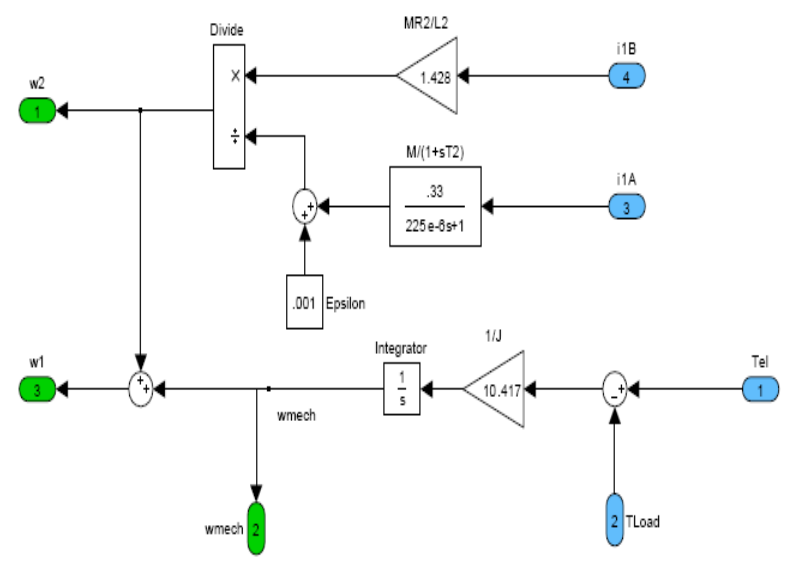

Fig. 9 Block diagram of Mechanical part

By using instantaneous values of $i_{g d}$ and $i_{\varepsilon q}, \omega_{r}$ could be

found, plus with motor mechanical speed ( $\omega_{\text {mach }}$ )

produce $\omega_{g}$. To prevent dividing by zero in simulation, we need to add a negligible constant (Epsilon in Fig.9). Output of mechanical part use for mechanical angle $\left(\chi_{r}\right)$, rotor flux angle toward stator and mechanical speed from speed sensor calculation. From Fig. 9, inputs of machine are produce converter voltage and load torque. Outputs of machine are three phase currents, mechanical speed and rotor flux angle. Currents and mechanical speed go to sensor block and rotor flux angle go to composite observer in control system.

\section{B. Simulation of Sensors Model}

Speed and current sensors block diagram are shown in Fig. 10.
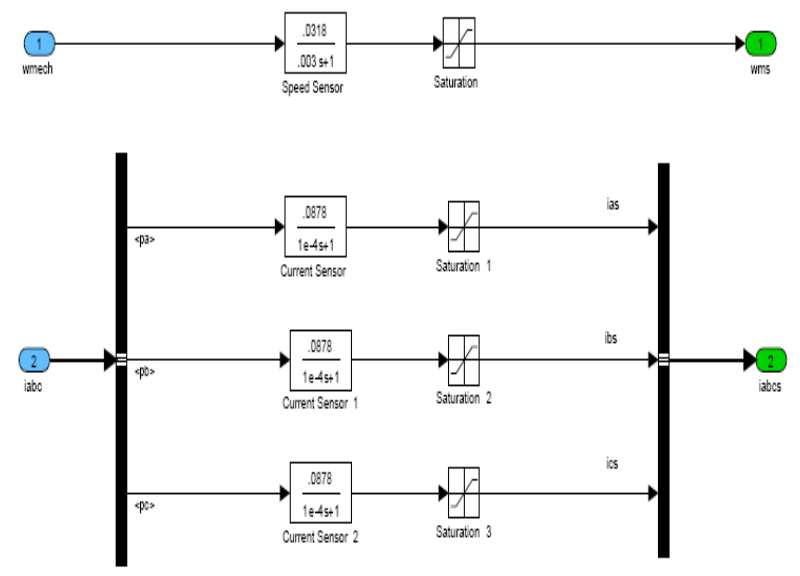

Fig. 10 Speed \&current sensors block diagram

Saturation block limit the output of sensors between \pm 10 Volt. These operators prevent cross the nominal parameters of the induction machine and protect machine.

\section{Simulation of Power Electronics Converter Model}

Power electronic block diagram is shown in Fig. 11.

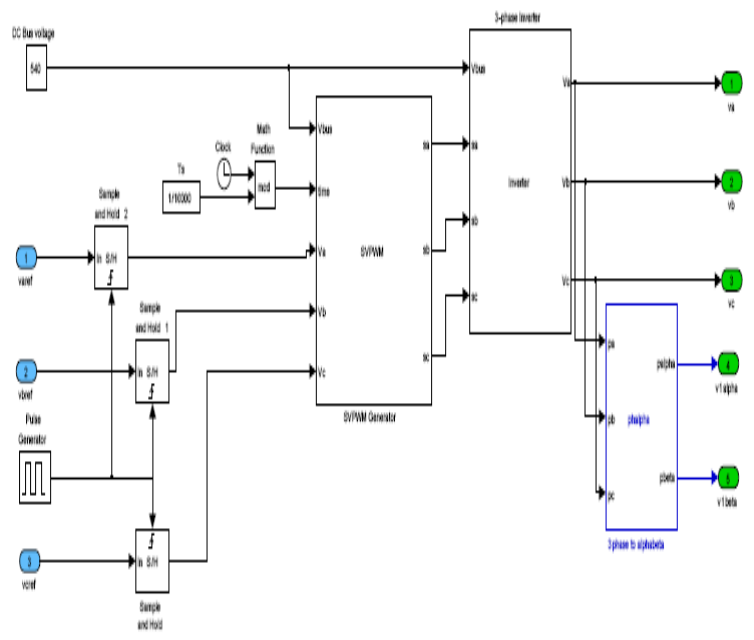

Fig. 11 Speed \&current sensors block diagram

Sample and hold blocks sampling the reference voltage values in per $0.1 \mathrm{mili}$ second (Ts). Proper switching algorithm implemented in SVPWM Generator and sa, sb and sc are produced switching algorithm. Since connection of machine is delta, voltage values are calculated and given by stator of machine. Reference voltages $\alpha-\beta$ are used in rotor flux observer block.

\section{Simulation of Control System Model}

In this system rotor flux observer, current, flux and speed controller are designed. Rotor block composite observer is shown in Fig. 12. 


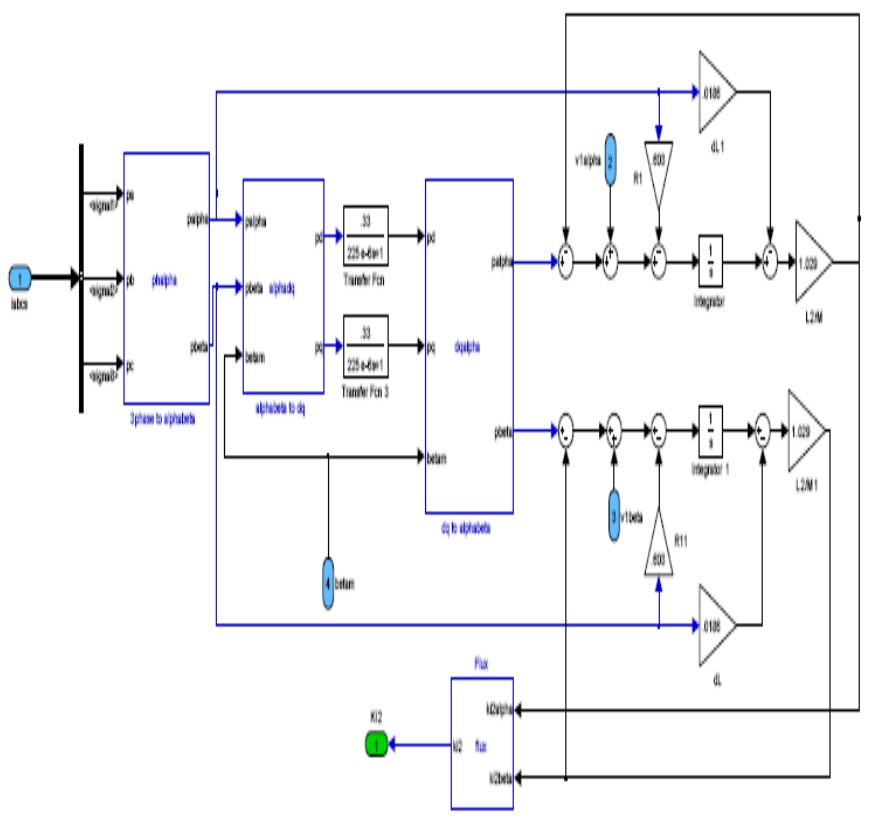

Fig. 12 Rotor flux observer based on composite voltage and current model

Now rotor flux estimate by measuring currents and machine voltages. Control system block diagram is shown in Fig. 13.

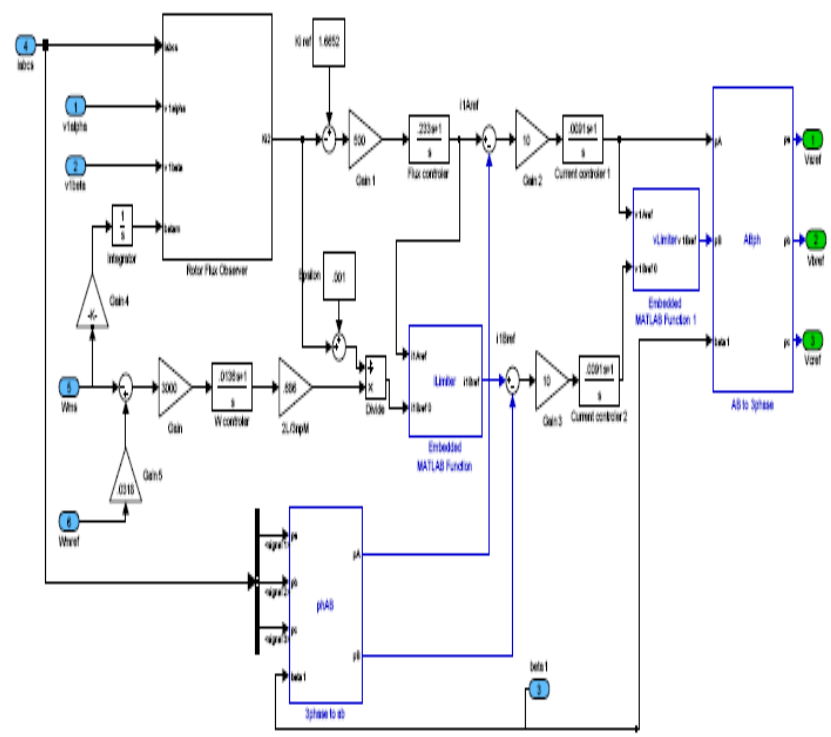

Fig. 13 Control system\& block diagram

In this figure, rotor reference flux in base speed region is equal to nominal flux.

Speed reference values are free, but we limit voltage and current reference on axis-B by means of 'I limiter' and ' $\mathrm{V}$ limiter' that coming follow, $\sqrt{1_{\max }{ }^{2}-1_{1 \text { Aref }}{ }^{2}}$ and $\sqrt{v_{\max }{ }^{2}-v_{1 \text { Aref }}{ }^{2}}$.

\section{Simulation Result}

For testing simulation, by giving nominal torque to system can be saw input current value. Nominal torque is:

$$
\mathrm{T}_{\mathrm{n}}=49.48 \quad \mathrm{~N} . \mathrm{m}
$$

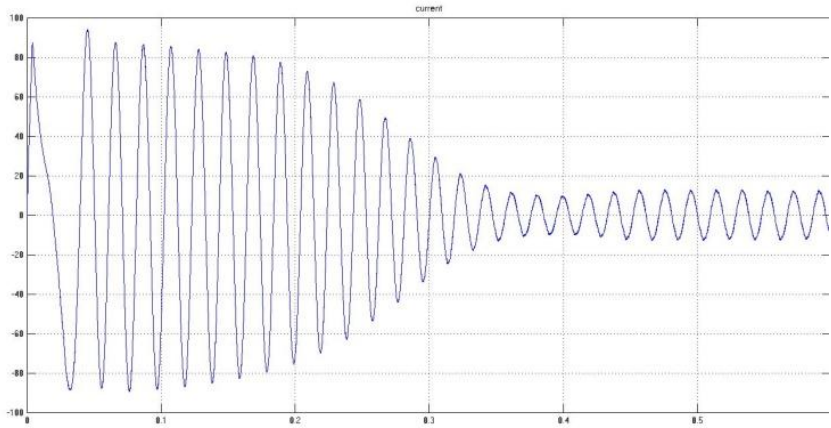

Fig. 14 Input current of machine

Output of voltage model observer and current model observer on $5 \%$ nominal speed $(15.16 \mathrm{rad} / \mathrm{s})$ are shown in Fig.14 and Fig.15 .output on 90\% nominal speed (272.85 $\mathrm{rad} / \mathrm{s})$ are in Fig.16 and Fig.17.

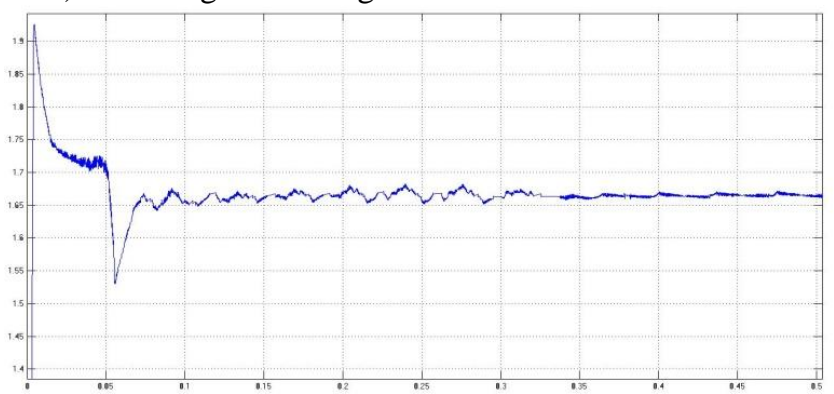

Fig.15 Output of voltage model observer on 5\%nominal speed

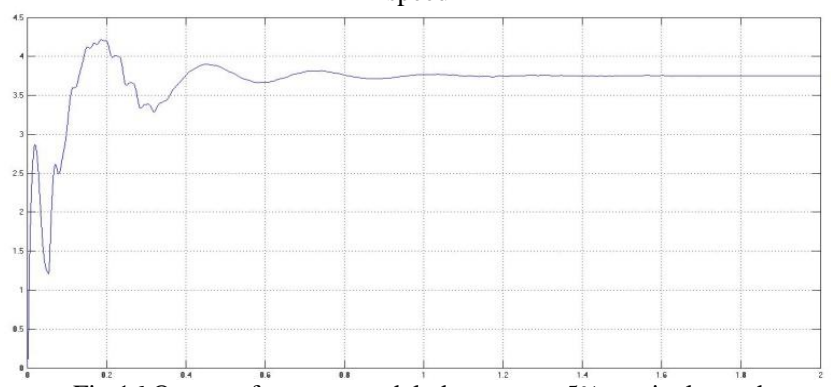

Fig.16 Output of current model observer on $5 \%$ nominal speed

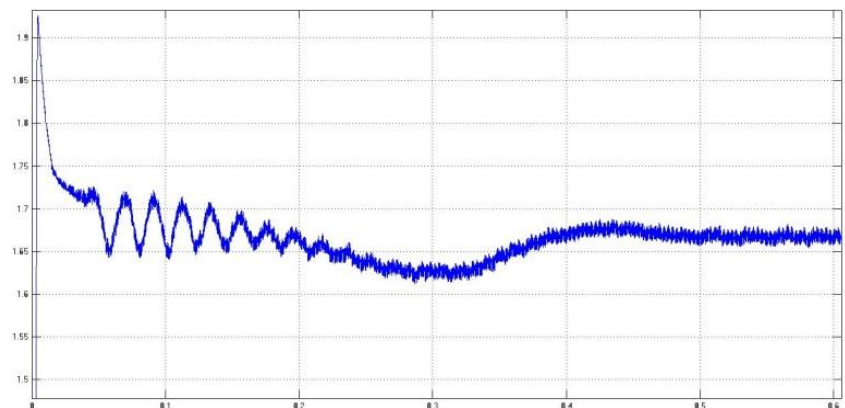

Fig. 17 Output of voltage model observer on $90 \%$ nominal speed

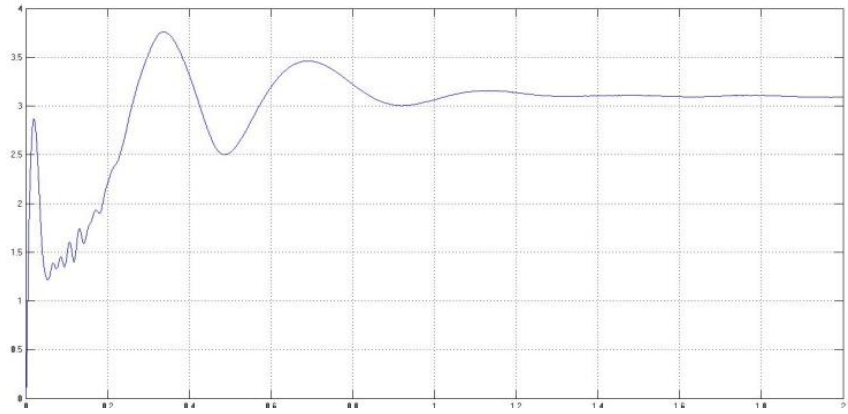

Fig. 18 output of current model observer on $90 \%$ nominal speed 


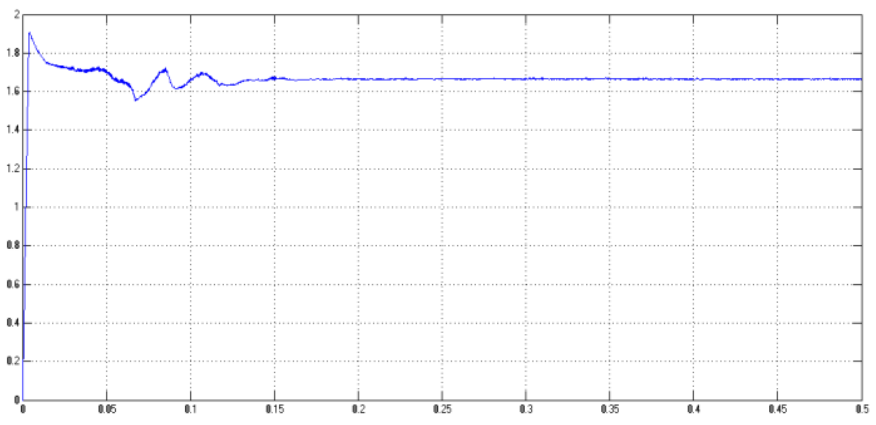

Fig.19 Output of composite model observer on 5\% nominal speed

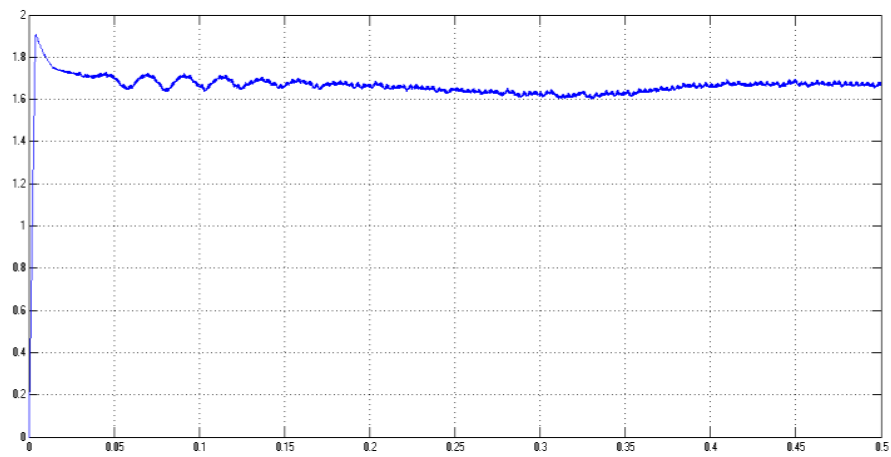

Fig.20 Output of composite model observer on $90 \%$ nominal speed

Operation in 5\% nominal speed (15.16 rad/s) with half nominal load

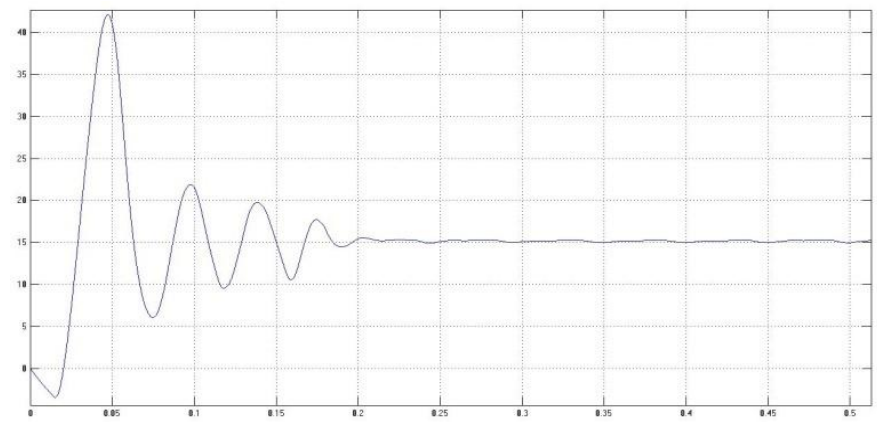

Fig. 21 Mechanical speed

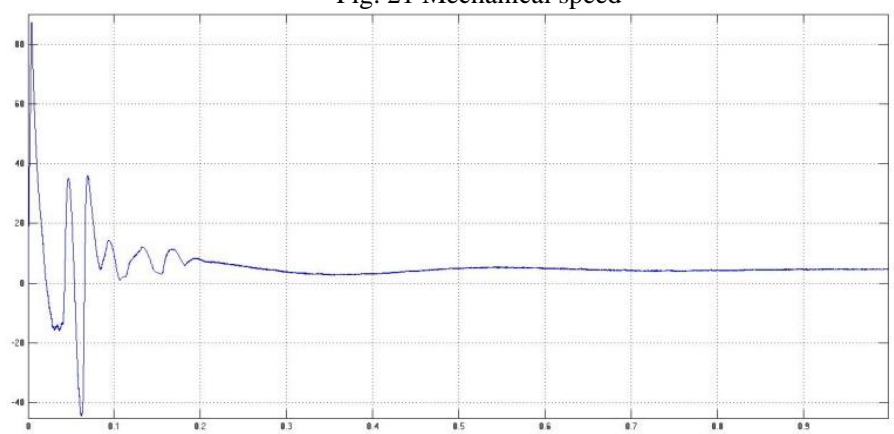

Fig. 22 Stator current on axis-A

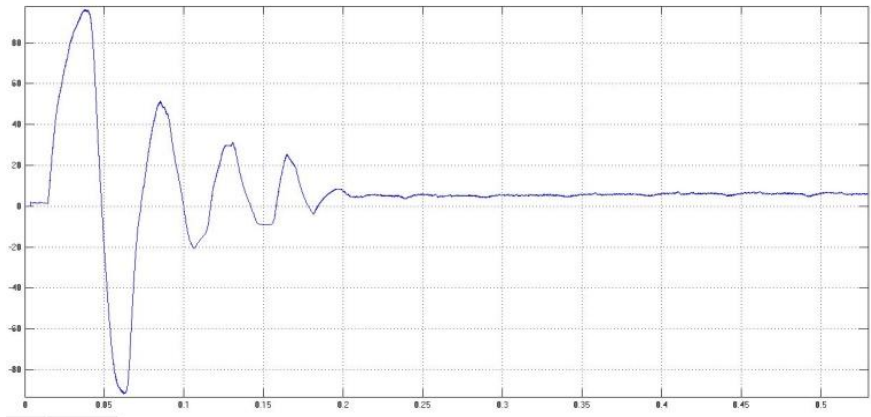

Fig. 23 Stator current on axis-B

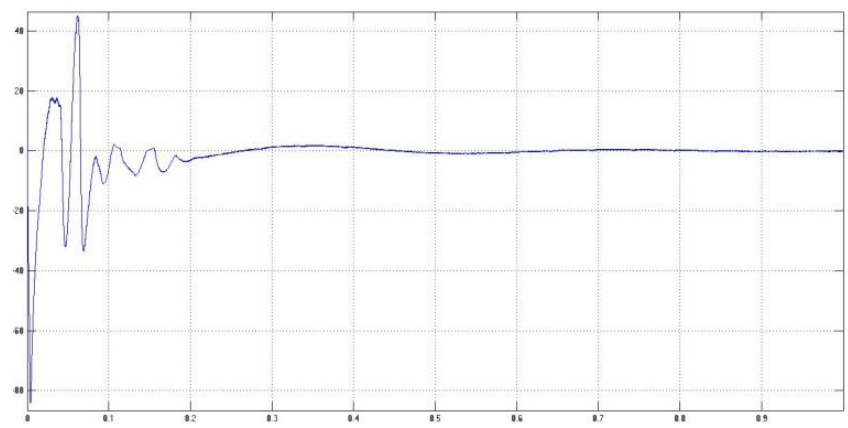

Fig. 24 Rotor current on axis-A

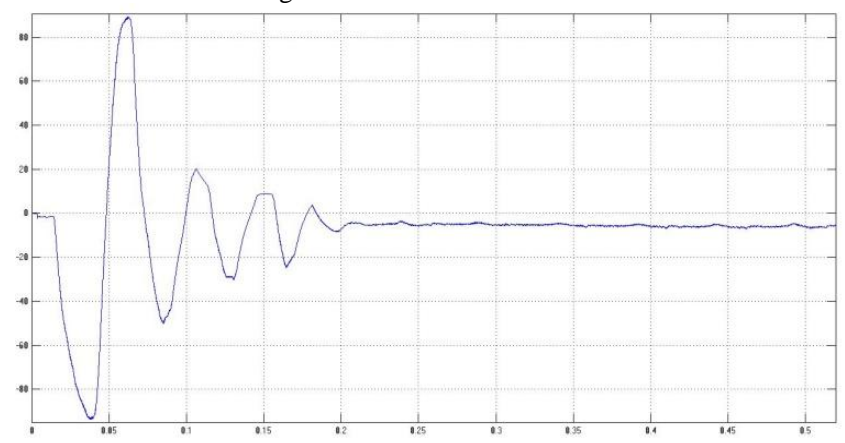

Fig. 25 Rotor current on axis-B

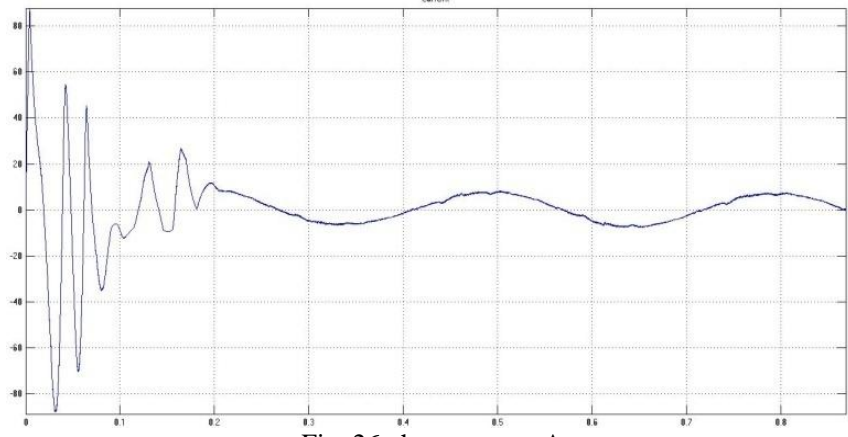

Fig. 26 phase current A

On previous operation point, reference speed grows up $10 \%$ with a step.

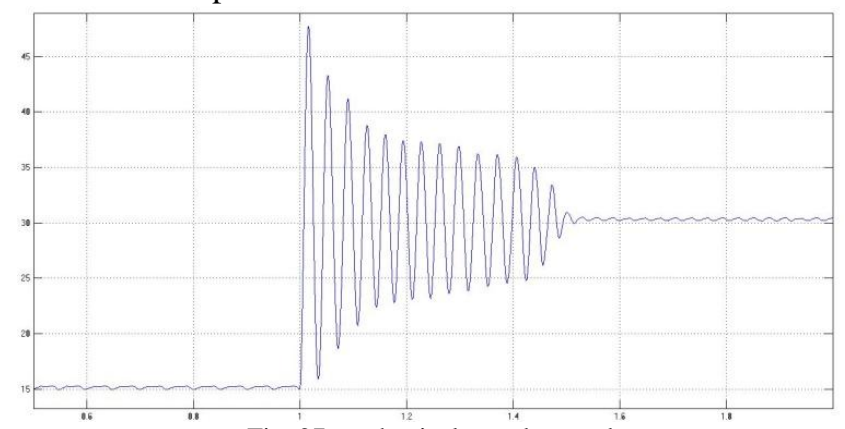

Fig. 27 mechanical speed toward time

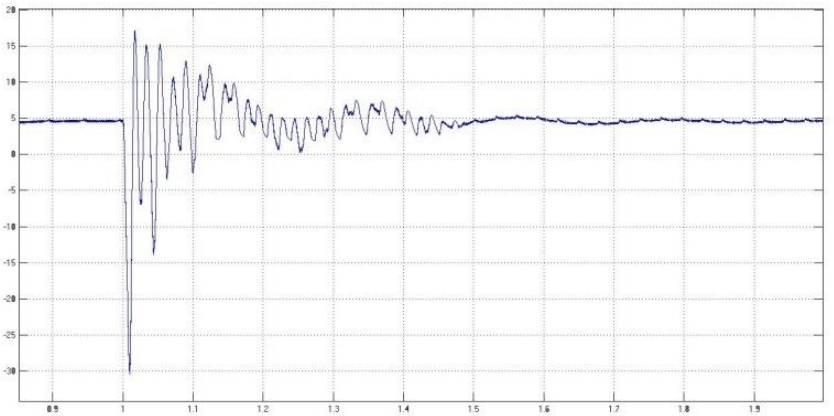

Fig. 28 Stator current on axis-A 


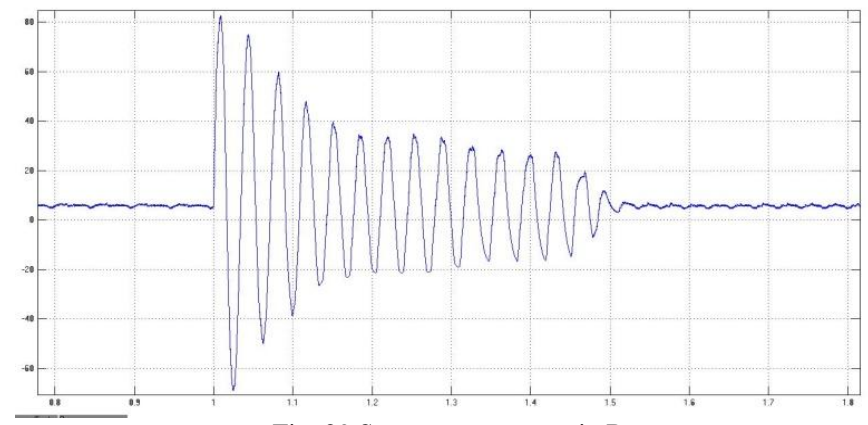

Fig. 29 Stator current on axis-B

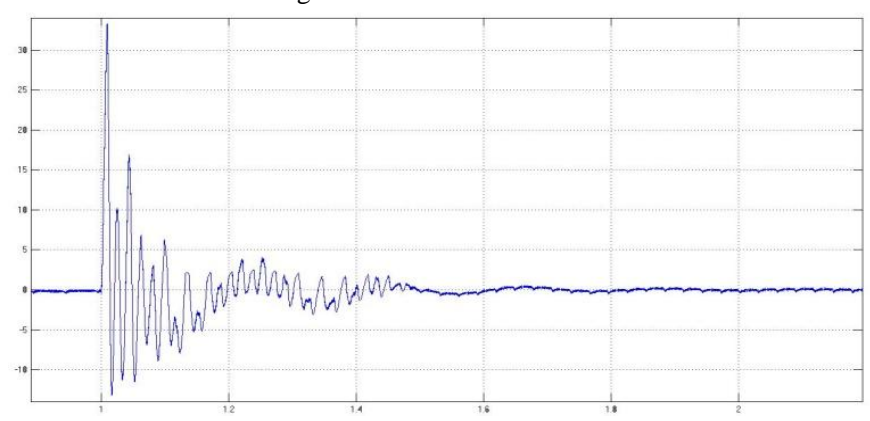

Fig. 30 Rotor current on axis-A

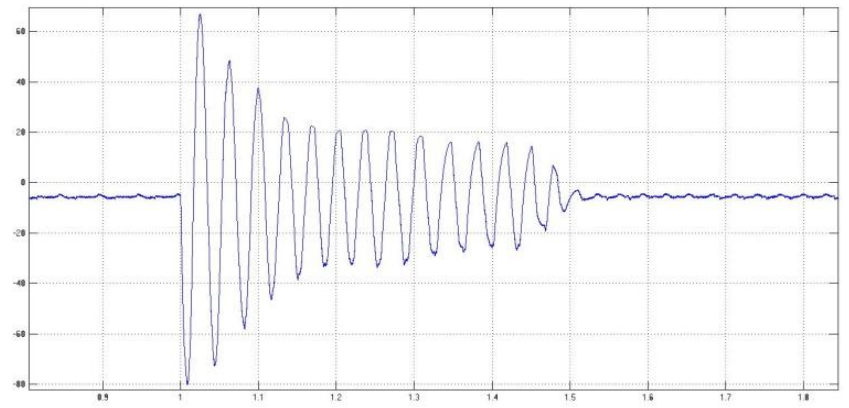

Fig. 31 Rotor current on axis-B

\section{CONCLUSION}

In this paper, a simulation study of the vector controlled induction motor drive has been done. A high performance vector controlled drive employing the rotor flux observer has been presented. Estimation of electric machine parameters is very important for variable speed control using field orientation techniques which are very popular in building services systems such as elevator drives, fan drives and pumps etc. Instead of the CM and VM observer models in the vector controlled drive system, the use of the composite model observer has made the drive system capable of operating in entire speed range with more acceptable performance. Comparison between CM and VM shows: 1- In Fig. 14 system is stable around 0.5 second. 2- Fig. 15 - Fig. 18 shows that voltage observer model (VM) have good performance vs. current observer model (CM) in low speed and vice versa in high speed. 3-Voltage observer model have high frequency noise when speed increase. Composite flux observer that shows in Figs.19-20 has good performance in wide range speed and stable very quickly. The simulation results agree with the nature of high performance motor drive system.

\section{APPENDIX}

The ratings of the three phase squirrel cage induction motor and power electronics converter are:

\begin{tabular}{|c|c|}
\hline Parameter & Parameter \\
\hline Nominal power $-\mathrm{Pn} \quad 15 \mathrm{kw}$ & $\begin{array}{l}\text { Stator linkage inductance -L } \sigma \mathrm{s} \\
4.72 \mathrm{mH}\end{array}$ \\
\hline $\begin{array}{l}\text { Nominal voltage-Vn } 380 \mathrm{v} \\
\& \Delta \text { connected }\end{array}$ & $\begin{array}{l}\text { Stator inductance }-\mathrm{Ls} \\
334.95 \mathrm{mH}\end{array}$ \\
\hline Nominal current-In $31 \mathrm{~A}$ & $\begin{array}{l}\text { Rotor linkage inductance -L } \sigma \mathrm{r} \\
4.72 \mathrm{mH}\end{array}$ \\
\hline Nominal speed-Nn $2895 \mathrm{rpm}$ & $\begin{array}{l}\text { Rotor inductance }-\mathrm{Lr} \\
334.95 \mathrm{mH}\end{array}$ \\
\hline Pole & Stator resistance-Rs $0.603 \Omega$ \\
\hline Nominal frequency-f $50 \mathrm{~Hz}$ & Rotor resistance- $\mathrm{Rr} \quad 1.467 \Omega$ \\
\hline $\begin{array}{l}\text { Mutual inductance-Lm } \\
330.23 \mathrm{mH}\end{array}$ & Rotor Inertia-Jm $\quad 0.046 \mathrm{Kgm}$ \\
\hline Switching frequency $10 \mathrm{KHz}$ & Current sample period $100 \mu \mathrm{s}$ \\
\hline $\begin{array}{l}\text { Dead time between pulses } \\
6 \mu \mathrm{s}\end{array}$ & Speed calculation period $3 \mathrm{~ms}$ \\
\hline DC line voltage $\quad 540 \mathrm{~V}$ & $\begin{array}{l}\text { Modulation method } \\
\text { SVPWM }\end{array}$ \\
\hline
\end{tabular}

\section{REFERENCES}

[1] P. A. S. De Wit, R. Ortega, and I. Mareels. Indirect field-oriented control of induction motors is robustly globally stable, Automatica, Vol. 32, No. 2, 1996.

[2] P.L. Jansen, R.D. Lorenz, and D.W. Novotny. Observer-based direct field orientation: analysis and comparison of alternative methods, IEEE Transactions on Industry Applications, Volume 30, Issue 4, July-Aug., 1994.

[3] X. Xu, R. De Doncker and D. Novotny. A stator flux oriented induction machine drive, In: IEEE Power Electronics Specialists Conference, Kyoto, Japan, 1988.

[4] D. Seyoum, D. McKinnon, M.F. Rahman, and C. Grantham. Offset compensation in the estimation of flux in induction machines, In: 29thAnnual Conference of the IEEE Industrial Electronics Society, Volume2, 2-6 Nov. 2003.

[5] M.-H. Shin, D.-S. Hyun, S.-B. Cho, and S.-Y. Choe. An improved stator flux estimation for speed sensorless stator flux orientation control of induction motors. IEEE Trans. Power Electron., Vol. 15, No. 2, Mar.,2000.

[6] B.K. Bose, Ed., Power Electronics and Variable Frequency Drives. Piscataway, NJ: IEEE Press, 1996.

[7] L. Harnefors. Design and analysis of general rotor-flux-oriented vector control systems, IEEE Transactions on Industrial Electronics, Volume48, Issue 2,April, 2001.

[8] P.L. Jansen and R.D. Lorenz. A physically insightful approach to the design and accuracy assessment of flux observers for field oriented induction machine drives, IEEE Transactions on Industry Applications, Volume 30, Issue 1, Jan.-Feb., 1994.

[9] M.L.de Aguiar, M. M. Cad,"The concept of complex transfer functions applied to the modeling of induction motors," Power engineering Society Winter Meeting, 2000, pp. $387-391$.

[10] A. Dumitrescu, D. Fodor, T. Jokinen, M. Rosu, S. Bucurecio," Modelling and simulation of electric drive systems using Matlab/Simulink environments, " International Conference on Electric Machines and Drives(IEMD), 1999, pp, 451-453.

[11] S. Wade, M. W. Dunningan, B. W. Williams," Modeling and simulation of induction machine vector control with rotor resistance identification," IEEE Transactions on Power Electronics, vol.12, no.3 , May 1997 , pp. 495-506.

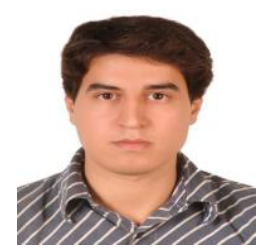

First A. Morteza Fazly was born in Hamedan, Iran, on 1987. He received the B.S. degree in Electrical Engineering from Shahid Rajaee university, Tehran, Iran, in 2009. He is the master student in the Sharif University of Technology, Department of Electrical Engineering, Tehran, Iran. His research activities include Control of Power Electronics, Control of Electric Machines and Power Quality.

The Author is with the Department of Electrical Engineering, Sharif University of Technology, Azadi St. Tehran Iran.

E-mail: Fazly@ee.sharif.ir , mortezafazly@gmail.com . 
Second B. Seyed Zeinolabedin Moussavi is a professor at Electrical Engineering Faculty of Shahid Rajaee University at Lavizan, Tehran, Iran. $\mathrm{He}$ teaches electromagnetism, linear control systems and network analysis. His researches interests related to above subjects. He chaired faculty for two terms as DEAN and for a term he was appointed as chancellor of University. Dr Moussavi is graduated from Czech Technical

University in Prague, Czech Republic. He used the opportunity and gets acquired with Polynomial Approaches at Czech Academy of Science. His knowledge in Czech language is fluent.

E-mail: SMoussavi@srttu.edu .

Website : http://s-moussavi.srttu.ir . 